\title{
CORRELATION OF RENAL DIMENSIONS AND GLOMERULAR FILTRATION RATE WITH HEIGHT, WEIGHT, BODY MASS INDEX, AND BODY SURFACE AREA IN CHILDREN
}

\author{
SHREYA CHOPRA*, SONAL CHAHAR, SAKET YADAV, KAKKAR MK \\ Department of Pediatrics, Mahatma Gandhi Medical College and Hospital, Jaipur, Rajasthan, Indi. Email: gurjardrrajesh4@gmail.com
}

Received: 14 April 2020, Revised and Accepted: 21 May 2020

ABSTRACT

Objective: The objective of the study was to estimate glomerular filtration rate (eGFR) and renal dimension and establish a correlation with age, weight, height, body mass index (BMI), and body surface area (BSA) of children and to measure renal dimensions (craniocaudal length, anteroposterior length, and transverse length) of both kidneys of 1-10 years children.

Methods: A total of 500 children from 1 to 10 years old were screened by ultrasonography to measure renal craniocaudal length, anteroposterior length, and transverse width of the kidney. Length, width, thickness, and cortical size of the kidneys were also measured.

Results: There was a positive correlation of renal dimension with age, weight, height, BMI, and BSA. There also was a positive correlation of eGFR with other renal parameters.

Conclusion: Renal dimension and eGFR were correlate with age, weight, height, BMI, and BSA in children.

Keywords: Age, Weight, Height, Body mass index, Body surface area.

(C) 2020 The Authors. Published by Innovare Academic Sciences Pvt Ltd. This is an open access article under the CC BY license (http://creativecommons. org/licenses/by/4. 0/) DOI: http://dx.doi.org/10.22159/ajpcr.2020.v13i7.37906

\section{INTRODUCTION}

Kidney size and function are an important indicator not only to evaluate children with renal diseases but also to determine adequate organ growth.

It is known that early-life conditions such as maternal age and nutritional status during pregnancy influence growth patterns, body composition, and risk for noncommunicable chronic diseases in later life [1]. Kidney size and function are also a potential surrogate measurement for the number of nephrons, which are the structural and functional units of the kidneys. Since the number of nephrons is determined largely in prenatal life, suboptimal kidney growth and development in fetal life lead to a smaller number of nephrons [2]. Some lines of evidence suggest that retarded growth or small-for-gestational-age, low birth weight, and preterm babies have relatively smaller kidneys with a decreased number of nephrons [3].

The key marker of kidney function is the glomerular filtration rate (GFR). However, the precise measurement of GFR is invasive, timeconsuming, expensive, and technically difficult. Equations have been developed to predict kidney function using serum creatinine (sCrea) data combined with readily available indices of muscular mass such as gender, age, and weight [4].

The currently used GFR estimation formula (0.413 $\times$ height/ sCrea [mg/dl]) must consider sCrea levels as well as the body height [5] due to varying body composition (especially muscle mass) causing inter- and intra-patient variability in sCrea levels [6]. To estimate GFR in children, the original Schwartz formula developed in 1976 has been recently adapted to current methods of sCrea assay and its use is now recommended. Another locally adapted Schwartz formula to creatinine assay method has very good agreement with standardized creatinine measurement [7].

The best screening modality to evaluate renal insufficiency in patients is sonography [8]. As ultrasonographic findings such as echogenicity, longitudinal length, parenchymal, and cortical thickness represent irreversible changes, ultrasonography (USG) is a superior imaging tool when it comes to ascertaining the progression of the disease [9]

Body developments and functions are directly connected to the growth rate. The growth rate of renal length will be evaluated with the help of distinct measurements such as weight, height, and anthropometric parameters such as body mass index (BMI) [10]. The parameter like BMI, height, weight and other anthropometric tools useful in the treatment of children with chronic pyelonephritis, obstructive uropathy, and chronic glomerulonephritis in early childhood.. With the help of sonography reports, it is easy in identifying the patients of urolithiasis, cystic kidney diseases, malignancies, infections, vesicoureteral reflux, and renal transplant in elders as well as in children [11].

Kidney length and volume are very important parameters in clinical settings to detect renal disease and recurrent urinary tract infection [12]. Renal size and function depend on different factors, including gender, body size, and BMI. Ethnic differences, perhaps partly due to the above variables, are expected [13]. While data on normal ranges for renal dimensions are available from Western literature [14], little data are available from the Indian subcontinent. Indian data of renal size and its correlation with other anthropometric parameters in normal Indian children are based on studies with small sample size and sparse age distribution [15]. Therefore, this study was conducted on the performance of the most commonly used creatinine-based formulas in adults and children in a large cross-sectional cohort of adolescents and young adults with a broad spectrum of GFRs.

\section{METHODS}

\section{Sample size}

All children attending the pediatric outpatient department (OPD) and inpatient department in the study period, which fulfill the inclusion criteria of the study, were included in the study.

\section{Study period}

This study period was November 2017-December 2018. 
Study design

This was a hospital-based observational study.

\section{Setting}

Children 1-10 years attending pediatric OPD and admitted to pediatric ward of Mahatma Gandhi Hospital, Jaipur.

\section{Inclusion criteria}

The following will be included in the study:

- All children admitted to the pediatric ward and attending pediatric OPD.

\section{Exclusion criteria}

The following criteria were excluded from the study:

- Patients for whom the parents/guardian not signed the informed consent

- Patients suffering from renal disorders

- Patients in dehydration, shock, and dyselectrolytemia.

\section{Methodology}

A total of 500 children fulfilling the above inclusion criteria were enrolled in this study. Participants primarily consist of children 1-10 years attending pediatric OPD and admitted to in pediatric ward of mahatma Gandhi Hospital. Selected children were screened by USG to measure renal craniocaudal length, anteroposterior length, and transverse width of the kidney. Length, width, thickness, and cortical size of the kidneys were measured. The longitudinal dimensions of the kidney were measured in a section visually estimated to represent the longest longitudinal section. Both lower and upper poles were defined. If the long axis of the kidney cannot be obtained with the patient supine, coronal or sagittal view with the patient in decubitus position was obtained. Then, the width and thickness were measured in a section perpendicular to the long axis of the kidney, as assessed from the longitudinal image. The probe was thus not necessarily perpendicular to the skin. The level of this transverse section was intended to be placed quite close to the hilum of the kidney, but at the same time free of the pelvis. Width and thickness were then measured in two orthogonal directions. Renal volume was estimated from the three orthogonal measurements on the base of the ellipsoid formula $\left.\left[\mathrm{V}=(4 / 3)^{*} \pi \mathrm{abc}\right]\right)$.

USG machine-color Doppler USG system, model-TUX-X 100 XARIA 100 urea/creatinine machine-VITROS 5600

Anthropometric measurements of the child (height, weight, BMI, and BSA) will be calculated.

BMI = Weight $(\mathrm{kg}) /$ height $^{2}\left(\mathrm{~m}^{2}\right)$

$$
\mathrm{BSA}=\sqrt{\frac{\text { Height }(\mathrm{cm}) \times \text { Weight }(\mathrm{kg})}{3600}}
$$

Estimate GFR (eGFR) of children will be calculated using modified Schwartz formula.

$$
\text { eGFR }(\text { modified Schwartz })=\mathrm{k} \times \frac{\text { height }(\text { in } \mathrm{cm})}{\text { Serum creatinine }(\mathrm{mg} / \mathrm{dL})}
$$

\section{Statistical analysis}

The data were coded and entered into a Microsoft Excel spreadsheet. The analysis was done using SPSS version 20 (IBM SPSS Statistics Inc., Chicago, Illinois, USA) Windows software program. Descriptive statistics included computation of percentages, means, and standard deviations. The data were checked for normality before statistical analysis using the Shapiro-Wilk test. The analysis of variance (for quantitative data within three groups) was used for quantitative data comparison of all clinical indicators. Pearson correlation test was used to correlate independent and dependent variables. The level of significance was set at $\mathrm{p} \leq 0.05$.

\section{OBSERVATION AND RESULTS}

In our study, almost equal number of children have found in every age group (Table 1).

Male (57.4\%) children were consider slightly higher as compared to female children (42.4\%).

The mean score of height, weight, BMI, and BSA was 119.7, 23.4, 16.2, and 0.88 , respectively.

Improvement of height, weight, BMI, and BSA was observed as the age increases age; this was found statistically significant (Table 2).

Improvement of size, width, breadth, and volume and eGFR was observed as the age increases; this was found statistically significant (Table 3).

All independent variables showed positive correlation and significant results with all dependent variables.

All independent variables (size, width, breath, and volume) showed positive correlation and significant results with all dependent variables (eGFR) (Tables 4 and 5).

\section{DISCUSSION}

Ultrasound is the modality of choice to assess kidney size and morphology. It is lacks ionizing radiation, can be performed bedside and in real time, is well tolerated by the patient and parents, and the measurements are reproducible [16]. Sonography has become an important part of the pediatric imaging armamentarium, perhaps the most important. It is a safe technique to begin, as it does not use ionizing radiation, and intravenous contrast agents, although several ultrasound contrast agents have been recently developed that can increase the accuracy of the imaging examination, does not require sedation, and is easily available and reproducible [17].

A limited number of studies have measured normal kidney volume using various imaging methods [18]. Shin et al. [19] measured volume in the Korean population using multidetector computed tomography. Cheong et al. [20] measured kidney volume and kidney length using magnetic resonance imaging, which is expensive and time-consuming.

In the present study, renal dimensions (length, width, and breadth) were assessed in a sagittal view and transverse view with normal children with the prone position. The prime rationale was to evaluate the maximum renal dimensions in both planes. Sonography seems to be an optimal technique for estimating the renal parameters in children.

In children, the growth of organs is dependent on the growth of the child's body, and thus, the organ growth can be correlated with somatic parameters, such as height, weight, and body surface area (BSA) in addition to age $[18,21]$. The normal limits of kidney size of healthy are helpful in differentiating renal conditions. This is of particular importance in childhood, when renal length changes with age, and when renal tract abnormalities exist, such as reflux nephropathy, renal hypoplasia obstructive uropathy, and renal agenesis. Many studies have reported the relationship between renal size and other anthropometric parameters (height, weight, BMI, and BSA) [22]. Body height and weight may vary with ethnicity [23].

There was a significant correlation of renal parameter (size, breadth, and width) and eGFR with age, body weight, height, and BSA in our study. Other studies have revealed similar results $[24,10]$.

All previous shows a significant correlation with age, height, and weight in different degrees from moderate to strong in Otiv et al. (India, 2012) [25] and Younus et al. (Pakistan, 2015) [26] they found good correlation with age but best with height, this study support that we found that the kidney length, width, breadth, and volume had the 
Table 1: Age-wise distribution of the study

\begin{tabular}{lll}
\hline Age (year) & Number of patients & Percentages \\
\hline 1 & 50 & 10 \\
2 & 53 & 10.6 \\
3 & 45 & 9 \\
4 & 59 & 11.8 \\
5 & 65 & 13 \\
6 & 42 & 8.4 \\
7 & 49 & 9.8 \\
8 & 47 & 9.4 \\
9 & 42 & 8.4 \\
10 & 48 & 9.6 \\
Total & 500 & 100 \\
\hline
\end{tabular}

Table 2: Age-wise distribution of the study according to anthropometry parameters

\begin{tabular}{lllll}
\hline $\begin{array}{l}\text { Age } \\
\text { (years) }\end{array}$ & $\begin{array}{l}\text { Weight (kg) } \\
\text { (mean } \pm \text { SD) }\end{array}$ & $\begin{array}{l}\text { Height }(\mathbf{c m}) \\
\text { (mean } \pm \text { SD) }\end{array}$ & $\begin{array}{l}\text { BMI } \\
\text { (mean } \pm \text { SD) }\end{array}$ & $\begin{array}{l}\text { BSA } \\
\text { (mean } \pm \text { SD) }\end{array}$ \\
\hline 1 & $8.79 \pm 0.2$ & $72.55 \pm 2.61$ & $15.7 \pm 0.01$ & $0.42 \pm 0.01$ \\
2 & $10.1 \pm 0.5$ & $80.5 \pm 2.15$ & $15.6 \pm 0.01$ & $0.45 \pm 0.01$ \\
3 & $11.66 \pm 0.41$ & $88.56 \pm 3.62$ & $14.9 \pm 0.01$ & $0.53 \pm 0.02$ \\
4 & $13.14 \pm 0.2$ & $95.23 \pm 3.22$ & $14.5 \pm 0.01$ & $0.66 \pm 0.01$ \\
5 & $14.65 \pm 0.52$ & $102.67 \pm 4.4$ & $13.9 \pm 0.01$ & $0.69 \pm 0.02$ \\
6 & $16.7 \pm 0.55$ & $109.1 \pm 5.2$ & $14 \pm 0.01$ & $0.73 \pm 0.01$ \\
7 & $18.1 \pm 0.75$ & $111.23 \pm 2.3$ & $14.6 \pm 0.01$ & $0.80 \pm 0.01$ \\
8 & $20.51 \pm 1.03$ & $117.12 \pm 2.98$ & $14.9 \pm 0.01$ & $0.91 \pm 0.03$ \\
9 & $24.4 \pm 0.87$ & $127.6 \pm 1.56$ & $15.1 \pm 0.01$ & $0.99 \pm 0.01$ \\
10 & $26.22 \pm 0.72$ & $131.5 \pm 2.93$ & $15.2 \pm 0.01$ & $1.05 \pm 0.02$ \\
p-value & $0.001(\mathrm{~S})$ & $0.001(\mathrm{~S})$ & $0.001(\mathrm{~S})$ & $0.001(\mathrm{~S})$ \\
\hline
\end{tabular}

BMI: Body mass index strongest correlation with height but correlated well with all variables, and therefore, could be used interchangeably.

Gavela et al. (2006) [23] include 474 children and reported height as most a sensitive indicator of kidney size Christophe et al. [27] also found a slight difference between kidney lengths and considered it negligible. The best correlation of renal size with weight was previously exhibit by Safak et al. [21] which was also consistent with our study. Kim et al. [18] documented that kidney length correlates positively with body length and weight. Soyupak et al. [28] also agreed with the same results. The body proportion is significantly distinct between boys and girls, but their renal length did not manifest a remarkable difference. Ganesh et al. [15] also describe this correlation. BMI is one of the extensively measured criteria for checking obesity. The BSA and lean body mass are considered as important factors in determining renal dimension in children [29].

BMI is one of the widely-used parameters for measuring obesity. There are several studies which evaluate BSA and lean body mass as a predictor of renal size in healthy children [30]. Zuzuárregui et al. [31] stated that BMI is greatly interacted with renal length. Renal development is rapid during fetal and early infant life, and the then growth rate progressively slows through the rest of the $1^{\text {st }}$ year of life and becomes finally stable. Akhavan et al. [32] reported that renal length increased with age. Normal values of the organ's weight and size modify with time presumably under the effect of hereditary components and surroundings such as routine diet, water intake, and environmental variations between ethnicity [33].

Our study revealed a significant correlation between kidney volume and independent variables. Kidney volume correlated better with BMI than in previous studies. In contrast to previous reports, Okur

Table 3: Age-wise distribution of the study according to renal parameters

\begin{tabular}{|c|c|c|c|c|c|}
\hline Age (years) & Size (mean \pm SD) & Width (mean \pm SD) & Breadth (mean $\pm S D)$ & Volume (mean \pm SD) & eGFR (mean \pm SD) \\
\hline 1 & $5.66 \pm 0.11$ & $2.35 \pm 0.02$ & $2.74 \pm 0.01$ & $21.79 \pm 1.11$ & $109.2 \pm 0.01$ \\
\hline 2 & $6.2 \pm 0.13$ & $2.81 \pm 0.09$ & $2.96 \pm 0.01$ & $26.57 \pm 1.56$ & $110.1 \pm 0.01$ \\
\hline 3 & $6.45 \pm 0.11$ & $2.92 \pm 0.05$ & $3.11 \pm 0.05$ & $28.77 \pm 1.04$ & $111.01 \pm 0.01$ \\
\hline 4 & $6.75 \pm 0.12$ & $3.01 \pm 0.06$ & $3.26 \pm 0.06$ & $34.69 \pm 1.61$ & $112.12 \pm 0.01$ \\
\hline 5 & $6.8 \pm 0.11$ & $3.05 \pm 0.08$ & $3.3 \pm 0.05$ & $34.11 \pm 1.24$ & $113.2 \pm 0.01$ \\
\hline 6 & $6.83 \pm 0.15$ & $3.19 \pm 0.05$ & $3.36 \pm 0.04$ & $36.23 \pm 0.78$ & $114.1 \pm 0.01$ \\
\hline 7 & $7.23 \pm 0.15$ & $3.22 \pm 0.09$ & $3.44 \pm 0.06$ & $41.7 \pm 1.26$ & $115.6 \pm 0.01$ \\
\hline 9 & $8.01 \pm 0.012$ & $3.41 \pm 0.1$ & $3.71 \pm 0.05$ & $53.66 \pm 1.3$ & $117 \pm 0.01$ \\
\hline 10 & $8.09 \pm 0.13$ & $3.51 \pm 0.11$ & $3.79 \pm 0.07$ & $55.19 \pm 2.01$ & $117.5 \pm 0.01$ \\
\hline p-value & $0.001(\mathrm{~S})$ & $0.001(\mathrm{~S})$ & $0.001(S)$ & $0.001(\mathrm{~S})$ & \\
\hline
\end{tabular}

eGFR: Estimate glomerular filtration rate

Table 4: Correlation between independent and dependent variables

\begin{tabular}{|c|c|c|c|c|c|}
\hline Independent variables & Size & Width & Breadth & Volume & GFR \\
\hline \multicolumn{6}{|l|}{ Age } \\
\hline Pearson r value & 0.96 & 0.63 & 0.52 & 0.95 & 0.91 \\
\hline p-value & $0.001(\mathrm{~S})$ & $0.001(\mathrm{~S})$ & $0.001(\mathrm{~S})$ & $0.001(\mathrm{~S})$ & $0.001(\mathrm{~S})$ \\
\hline \multicolumn{6}{|l|}{ Weight } \\
\hline Pearson $r$ value & 0.44 & 0.91 & 0.91 & 0.74 & 0.62 \\
\hline p-value & $0.001(\mathrm{~S})$ & $0.001(\mathrm{~S})$ & $0.001(\mathrm{~S})$ & $0.001(\mathrm{~S})$ & $0.001(\mathrm{~S})$ \\
\hline \multicolumn{6}{|l|}{ Height } \\
\hline Pearson $r$ value & 0.85 & 0.86 & 0.83 & 0.86 & 0.55 \\
\hline $\mathrm{p}$-value & $0.001(\mathrm{~S})$ & $0.001(\mathrm{~S})$ & $0.001(\mathrm{~S})$ & $0.001(\mathrm{~S})$ & $0.001(\mathrm{~S})$ \\
\hline \multicolumn{6}{|l|}{ BMI } \\
\hline Pearson r value & 0.77 & 0.68 & 0.77 & 0.81 & 0.77 \\
\hline p-value & $0.001(\mathrm{~S})$ & $0.001(\mathrm{~S})$ & $0.001(\mathrm{~S})$ & $0.001(\mathrm{~S})$ & $0.001(\mathrm{~S})$ \\
\hline \multicolumn{6}{|l|}{ BSA } \\
\hline Pearson r value & 0.85 & 0.91 & 0.88 & 0.75 & 0.81 \\
\hline p-value & $0.001(\mathrm{~S})$ & $0.001(\mathrm{~S})$ & $0.001(\mathrm{~S})$ & $0.001(\mathrm{~S})$ & $0.001(\mathrm{~S})$ \\
\hline
\end{tabular}

BMI: Body mass index 
Table 5: Correlation between eGFR and renal parameters

\begin{tabular}{|c|c|c|c|c|c|}
\hline Independent & Variables & Size & Width & Breadth & Volume \\
\hline \multirow[t]{2}{*}{ eGFR } & $\begin{array}{l}\text { Pearson r } \\
\text { value }\end{array}$ & 0.91 & 0.79 & 0.88 & 0.91 \\
\hline & $\mathrm{p}$-value & $0.001(\mathrm{~S})$ & $0.001(\mathrm{~S})$ & $0.001(\mathrm{~S})$ & $0.001(\mathrm{~S})$ \\
\hline
\end{tabular}

eGFR: Estimate glomerular filtration rate

et al. [34] revealed no significant difference between kidney volumes and measurements at any age.

\section{eGFR}

In children, the Schwartz formula is widely used to estimate GFR from creatinine concentrations Schwartz formula estimates GFR using creatinine concentrations and child height. It has previously been reported that lean body mass, indicating muscular mass, is an important determinant of the GFR [35]. So far, comparing the effects of anthropometric measures on creatinine and cystatin $C$ concentrations and their derived eGFR are contradictory. Next to BMI, we observed that age, height, weight, and BSA and were positive correlation with eGFR which was similar to Miliku et al. [36]. Studying detailed measures of body composition will, therefore, likely add to the understanding of the associations of body composition and kidney function measures.

\section{Limitations of the study}

The study was retrospective, but renal length measurements were routinely performed by experienced sonographers following standard protocol during the USG examinations and were rechecked by pediatric radiologists. Furthermore, differences in ultrasonographic techniques, patient positioning, and cursor placement can affect the reproducibility of measurements on renal length. Therefore, future prospective studies evaluating intra- and inter-observer agreements are necessary.

Although the sample was not randomly chosen from different parts of the country and thus, the results may be generalizable. Due to the large sample size, this study represents the population more closely. However, the socioeconomic status of children examined was not recorded, although they typically belonged to lower-middle and lowerincome groups. Considering the large population of India, the study did not consider parameters such as race, culture, income group, and rural or urban origin.

\section{CONCLUSION}

In clinical practice, body height and weight can be quickly recorded to compare the actual renal length with the renal norm. Since the estimation of renal volume requires the measurement of three dimensions of the kidney, the error associated with renal volume increases in geometric proportion. Hence, it is simpler to use renal length as a yardstick for comparing renal growth with body growth. Due to the large sample size, this study represents the population more closely. The renal size norms developed by this study provide normal kidney length and volume range for children according to age.

\section{AUTHORS' CONTRIBUTIONS}

I would like to express my heartiest gratitude to the participants who gave the willingness to participate in the study.

\section{CONFLICTS OF INTEREST}

There are no conflicts of interest.

\section{AUTHORS' FUNDING}

Self.

\section{REFERENCES}

1. Luyckx VA, Bertram JF, Brenner BM, Fall C, Hoy WE, Ozanne SE, et al. Effect of fetal and child health on kidney development and longterm risk of hypertension and kidney disease. Lancet 2013;382:273-83.
2. Geelhoed JJ, Verburg BO, Nauta J, Lequin M, Hofman A, Moll HA, et al. Tracking and determinants of kidney size from fetal life until the age of 2 years: The Generation R study. Am J Kidney Dis 2009;53:248-58.

3. Abitbol CL, DeFreitas MJ, Strauss J. Assessment of kidney function in preterm infants: Lifelong implications. Pediatr Nephrol 2016;31:2213-22.

4. Kasiske BL, Keane WF. Laboratory assessment of renal disease: Clearance, urinalysis, and renal biopsy. In: Brenner BM, editor. Brenner \& Rector's the Kidney. Philadelphia, PA: WB Saunders; 1996. p. 1129-63.

5. Schwartz GJ, Munoz A, Schneider MF, Mak RH, Kaskel F, Warady BA, et al. New equations to estimate GFR in children with CKD. J Am Soc Nephrol 2009;20:629-37.

6. Sambasivan AS, Lepage N, Filler G. Cystatin C intrapatient variability in children with chronic kidney disease is less than serum creatinine. Clin Chem 2005;51:2215-6.

7. Bacchetta J, Cochat P, Rognant N, Ranchin B, Hadj-Aissa A, Dubourg L. Which creatinine and cystatin $\mathrm{C}$ equations can be reliably used in children? Clin J Am Soc Nephrol 2011;6:552-60.

8. Khati NJ, Hill MC, Kimmel PL. The role of ultrasound in renal insufficiency: The essentials. Ultrasound Q 2005;21:227-44.

9. O'Neill WC. Sonographic evaluation of renal failure. Am J Kidney Dis 2000;35:1021-38.

10. Kim BW, Song MK, Chung S, Kim KS. Evaluation of kidney size in children: A pilot study of renal length as a surrogate of organ growth. Korean J Pediatr 2012;55:54-7.

11. Wong IY, Copp HL, Clark CJ, Wu HY, Shortliffe LD. Quantitative ultrasound renal parenchymal area correlates with renal volume and identifies reflux nephropathy. J Urol 2009;182:1683-7.

12. Bakker J, Olree M, Kaatee R, De Lange EE, Moons KG, Beutler JJ, et al. Renal volume measurements: Accuracy and repeatability of US compared with that of MR imaging. Radiology 1999;211:623-8.

13. Okoye IJ, Agwu KK, Idigo FU. Normal sonographic renal length in adult Southeast Nigerians. Afr J Med Med Sci 2005;34:129-31.

14. Pruijm M, Ponte B, Ackermann D, Vuistiner P, Paccaud F, Guessous I, et al. Heritability, determinants and reference values of renal length: A family-based population study. Eur Radiol 2013;23:2899-905.

15. Ganesh R, Vasanthi T, Lalitha J, Rajkumar J, Muralinath S. Correlation of renal length with somatic variables in Indian children. Indian J Pediatr 2010;77:326-8

16. Geelhoed JJ, Kleyburg-Linkers VE, Snijders SP. Reliability of renal ultrasound measurements in children. Pediatr Nephrol 2009;24:1345-53.

17. Robbin ML. Ultrasound contrast agents: A promising future. Radiol Clin North Am 2001;39:399-414.

18. Kim JH, Kim MJ, Lim SH, Kim J, Lee MJ. Length and volume of morphologically normal kidneys in Korean children: Ultrasound measurement and estimation using body size. Korean J Radiol 2013;14:677-82

19. Shin HS, Chung BH, Lee SE, Kim WJ, Ha HI, Yang CW. Measurement of kidney volume with multi-detector computed tomography scanning in young Korean. Yonsei Med J 2009;50:262-5.

20. Cheong B, Muthupillai R, Rubin MF, Flamm SD. Normal values for renal length and volume as measured by magnetic resonance imaging. Clin J Am Soc Nephrol 2007;2:38-45.

21. Safak AA, Simsek E, Bahcebasi T. Sonographic assessment of the normal limits and percentile curves of liver, spleen, and kidney dimensions in healthy school-aged children. J Ultrasound Med 2005;24:1359-64.

22. Dhingra B, Sharma S, Mishra D, Kumari R, Pandey RM, Aggarwal S. Normal values of liver and spleen size by ultrasonography in Indian children. Indian Pediatr 2010;47:487-92.

23. Gavela T, Sánchez M, Gómez G, Gallego S, Martínez-Pérez J, Pintado MT. Ultrasonographic study of kidney size in children. Nefrología J 2006;26:325-9.

24. Haugstvedt S, Lundberg J. Kidney size in normal children measured by sonography. Scand J Uronephrol 1980;14:251-5.

25. Otiv A, Mehta K, Ali U, Nadkarni M. Sonographic measurement of renal size in normal Indian children. Indian Pediatr 2012;49:533-6.

26. Younus N, Raza F, Bhugio S, Zehra N, Gul P, Mehmood W, et al. Sonographic measurement of normal renal size and correlation with somatic variables in subset of Karachi pediatric population. Pak J Med Dent 2015;4:24-9.

27. Christophe C, Cantraine F, Bogaert C, Coussement C, Hanquinet S, Spehl M, et al. Ultrasound: A method for kidney size monitoring in children. Eur J Pediatr 1986;145:532-8.

28. Soyupak SK, Narli N, Yapicioglu H, Satar M, Sungur EH. Sonographic measurements of the liver, spleen and kidney dimensions in the healthy term and preterm newborns. Eur J Radiol 2002;43:73-8.

29. Schmidt IM, Mølgaard C, Main KM, Michaelsen KF. Effect of gender 
and lean body mass on kidney size in healthy 10-year-old children. Pediatr Nephrol 2001;16:366-70.

30. Adibi A, Adibi I, Khosravi P. Do kidney sizes in ultrasonography correlate to glomerular filtration rate in healthy children. Australas Radiol 2007;51:555-9.

31. Zuzuárregui JR, Mallios R, Murphy J. The effect of obesity on kidney length in a healthy pediatric population. Pediatr Nephrol 2009;24:2023-7.

32. Akhavan A, Brajtbord JS, McLeod DJ, Kabarriti AE, Rosenberg HK, Stock JA. Simple, age-based formula for predicting renal length in children. Urology 2011;78:405-10.

33. Caglar V, Kumral B, Uygur R, Alkoc OA, Ozen OA, Demirel H. Study of volume, weight and size of normal pancreas, spleen and kidney in adults autopsies. Forensic Med Anat Res 2014;2:63-9.

34. Okur A, Serin HI, Zengin K, Erkoc MF, Tanık S, Yıldırım U. Relationship between kidney volume and body indexes in the Turkish population determined using ultrasonography. Int Braz J Urol 2014;40:816-22.

35. Chew-Harris JS, Florkowski CM, Elmslie JL, Livesey J, Endre ZH, George PM. Lean mass modulates glomerular filtration rate in males of normal and extreme body composition. Intern Med J 2014;44:749-56.

36. Miliku K, Bakker H, Dorresteijn EM, Cransberg K, Franco OH. Childhood estimates of glomerular filtration rate based on creatinine and cystatin C: Importance of body composition. Am J Nephrol $2017 ; 45: 320-6$ 